\title{
The What, Why and How of Conducting Focus-Group Research
}

\author{
Fatimah Almutrafi \\ College of Languages and Translation, King Saud University, Riyadh, Saudi Arabia
}

\section{Email address:}

falmutrafi@kus.edu.sa

\section{To cite this article:}

Fatimah Almutrafi. The What, Why and How of Conducting Focus-Group Research. International Journal of Language and Linguistics. Vol. 7, No. 5, 2019, pp. 235-239. doi: 10.11648/j.ijl1.20190705.18

Received: February 17, 2019; Accepted: September 6, 2019; Published: September 21, 2019

\begin{abstract}
Qualitative research methodology is considered to be appropriate if a researcher plans to scrutinise a new area of study or research a topic when it is not suitable to use observational techniques such as attitudes and decision-making. The choice of any research methodology depends on the purpose of the research. In social science research, the three most common qualitative methods are observation, interviews, and focus groups. Each method is particularly suitable for obtaining a specific type of data. For example, the use of observation is suitable for collecting data on naturally occurring behaviour found in their usual contexts. Interviews are most appropriate for collecting data on people's personal histories, perspectives, and experiences, particularly when exploring sensitive topics. Focus groups are effective in obtaining information on how groups of individuals think or feel about a specific issue and they also give greater insight into why certain beliefs are held. This paper aims to highlight different issues with regard to using focus groups as a qualitative method in the field of social sciences that can be integrated into an overall study design or can occur independently when a specific issue is being investigated. It starts off with an overview of focus groups and presents the values and limitations of using focus groups followed by some principles for composing them. The paper also discusses the role of the moderator. It concludes with the ethical considerations that should be taken into account when planning to use the focus group methodology.
\end{abstract}

Keywords: Focus Groups, Qualitative Methods, Research Design

\section{Introduction}

Originally, focus groups were designed as a marketing research tool but they have since been adopted for research in many fields, including the social sciences. The method developed as a qualitative data collection approach and a linking strategy for scientific research and local knowledge [1]. It has been used for a range of different purposes, such as generating hypotheses, developing survey questions, or interpreting quantitative data. A focus group is defined as a "...carefully planned series of discussions designed to obtain perceptions on a defined area of interest in a permissive, nonthreatening environment" [2]. It is usually conducted with about seven to ten people by a trained interviewer. Participants in a focus group often share their ideas and perceptions in a relaxed, comfortable, and often enjoyable environment. When a focus group is correctly used, it can produce high quality data that leads to high quality decisionmaking, and it can provide valid and reliable information [3].
Focus groups are considered a type of group interview that exploit communication between research participants in order to generate data. Often, group interviews are used as a quick and suitable way of collecting data from a number of people at the same time. Also, group interaction is used explicitly as part of the method. Specifically, instead of the researcher asking each person to respond to a question individually, s/he encourages the participants to talk to each other, ask questions, exchange anecdotes and comment on each other's' experiences and viewpoints. It is a useful method for investigating people's knowledge and experiences and can be used to scrutinize not only what people think but also how they think and why they think that way [4]. Focus groups can be considered as "... a group of individuals selected and assembled by researchers to discuss and comment on, from personal experience, the topic that is the subject of the research" [5].

It is important to differentiate between focus groups and group interviewing [6]. Group interviewing entails 
interviewing many people at the same time, depending on questions and responses between the researcher and the participants. However, a focus group focuses on the interaction within the group based on issues that are provided by the researcher" [6]. Therefore, the main feature which differentiates focus groups from other group formats is the insight and data formed by the interaction between participants. Moreover, Focus groups can be self-contained; that is to say, a focus group can be used as the only method of data collection or it can be employed alongside other methods to achieve triangulation and to check the validity of the research [6].

The parameters for the development of focus groups were established in terms of ensuring that participants have a specific experience of, or opinion about, the topic under investigation; using a clear interview guide; exploring the participants' subjective experiences regarding predetermined research questions [7]. Focus group research aims to investigate participants' attitudes, perceptions, experiences and reactions in a way which would not be possible using other methods such as observation, individual interviewing, or questionnaires. These attitudes and perceptions are more likely to be exposed through a social gathering and through the interaction between the members of the focus group. It aims to elicit a multiplicity of views, feelings and beliefs within a group context.

Furthermore, focus groups have a distinctive cluster of features as they involve homogeneous people in a social interaction and aim to collect qualitative data from a focused discussion [2]. But researchers should determine the purpose of their research first, then decide whether to use the focus group method or not. Similar to other research studies, the first step in any data collection method is to define the aim of the study. Sample purposes for a focus group include exploration, program development, systematic research and evaluation [8]. Exploration is represented in the researcher's aim to find out information about an issue of importance from the target population. For program development, researchers can ask members of the target population what kinds of activities they would enjoy. If the purpose of the research is to conduct systematic research, focus groups can help by collecting in-depth data on specific research questions. Also, focus groups can be used for evaluation purposes where researchers can obtain thorough data on specific evaluation questions in order to decide on program success or progress.

Comparing this method to other research methods such as observation, it seems that a focus group enables the researcher to obtain different information in a shorter period of time, whereas observational methods seem to have to wait for things to take place. In a focus group, the researcher uses an interview guide. Based on this, focus groups are not natural events but are prearranged and controlled. They are mainly valuable when (a) there exist differences between the participants and decision-makers or professionals in terms of power, (b) when the researcher is interested in the everyday use of language and the culture of some particular groups, or (c) when the degree of consensus on certain topics has to be explored [9].

It is noteworthy that some communities and organizations may use the focus group method inappropriately. For instance, they may generalise results of a single focus group as if it were a whole population. Or they might carry out a focus group immediately after a training course to evaluate the acquired knowledge on an individual basis on the part of the attendees. So, the question, in this respect is, how can a researcher determine whether a focus group is the best tool to use? It is emphasised that focus groups ".... are not a tool for building a consensus, educating, or for evaluating the impact of an educational event [10]. These purposes are better served by other methods." They further clarify that the focus group process depends on an open and trusting environment in which no attempt is made to convince the participants or change their attitudes.

Any effort to achieve a consensus has the potential to depress divergent thinking which could have an impact on the quality of the focus group results [10]. They suggest four uses of focus groups; i.e., they can be used to (a) gain clarity on how people experience a programme, (b) create information on participants' attitudes and values, (c) provide information on the language used by potential survey respondents, and (d) add detail to information generated by a quantitative survey. The more accurate the researcher is in planning, conducting and analysing the data, the more reliable the results will be. However, when this method is intended to be used with children, some modifications are required in terms of the moderator, the group composition, and the topics under discussions $[11,12]$.

\section{Values and Limitations of the Focus Group Method}

Interaction has been considered as the key feature of focus groups that is not feasible when using other methods It underlines how the participants view the world around them, the type of language they use to express their values about particular issues or situations and it provides participants with the ability to generate new ideas [4]. Additionally, information can be elicited in ways that allow researchers to discover why an issue is important, and what makes it important [13]. Thus, the gap between what participants say and what they actually do can be understood in a better way. In the event that different understandings are revealed by the participants, this paves the way for various explanations of their behaviour and attitudes. Focus groups may be employed at the preliminary stages of or during a study [14]. Additionally, focus groups could be used to evaluate a set of activities in order to assess their impact, or to create further research possibilities [15].

Furthermore, participants in focus group research can also benefit from participating in such a method. Participants will have the opportunity to be involved in different processes of 
decision making, to be appreciated as experts and work with researchers in a collaborative way [15]. Also, this qualitative tool can empower many participants, especially if those participants are actively involved in something which they think will be beneficial [4]. Another advantage is that these groups are considered as a cost effective method which can be used in a wide range of topics in the social sciences with different people [16]. Also, the detailed information produced by using such a method may increase its validity.

Kitzinger (1994) provides a plethora of core advantages to be gained from the interaction between participants. The interaction highlights the participants' attitudes, priorities, language and framework of understanding. It also encourages different types of communication and helps to identify group norms. Interaction provides insight into the operation of group and social processes in the articulation of knowledge and can encourage open conversation about embarrassing topics [4]. Furthermore, it facilitates the expression of ideas and experiences that might be left underdeveloped in an interview.

However, most, if not all research methods have some limitations. Some of them can be avoided by careful preparation and moderation; however, others are inevitable and peculiar to this method [13]. Specifically, a focus group is open ended in nature, and cannot be totally prearranged; the researcher has less control over the data than in other methods either quantitative or individual interviewing. The participants need to have the freedom to talk to each other and express their feelings and viewpoints. Although a focus group can provide reliable and more natural data that leads to essential insights about individuals' behaviour, it cannot be used to generalise the data in the same way as with survey research [17]. In fact, generalising findings to a whole population might be limited due to the small number of participants involved, who may not be considered to be a representative sample.

Another possible limitation is that focus groups may indeed discourage some people from participating in the research process such as reluctant or inarticulate persons, those who lack communication skills, or those who have special needs. These types of participants may feel discouraged when it comes to sharing sensitive or private information with others (e.g. sex issues and salaries). Also, it is not a reliable method for determining an individual's authentic standpoint as participants might be more supportive than honest [2]. In such cases, using one-to-one interviewing or other methods alongside a focus group might be beneficial and more appropriate. Essentially, focus groups are not entirely confidential or anonymous as the topic is shared with other members. In addition, such an approach cannot be the solution to all research problems [18].

\section{Composition of Focus Groups}

A lot of time is needed for organising focus group interviews, certainly more than is needed for conducting other types of interview. This method requires more preparation to get individuals to group gatherings and the need to plan suitable venues with sufficient recording facilities. Size and composition are essential variables in focus group methodology. The suggested number of participants in each group varies between researchers. The suitable number is six to ten [19], while others have used fifteen participants. Some even consider that four participants are enough to carry out a focus group [4]. The group meetings can be held in different places such as the participants' homes, rented facilities, or schools. However, [20] propose that neutral places can help to avoid negative or positive relations with a particular location or building.

Another crucial aspect that needs to be carefully considered is the choice of the participants for the focus groups. If a group is heterogeneous with regard to gender, class, or perspectives, the differences between its participants may noticeably affect their contributions, and can decrease the quality of the data. Participants may tend to censor their ideas to conform to those who differ from them in terms of power, status, profession, income, education, or even personal characteristics. Although, group members in focus group methodology should be homogeneous in respect of the relevant selection criteria, those members should be unknown to each other [21]. Some researchers argue that unacquainted participants can provide truthful and spontaneous answers $[1,22]$.

Age is considered as an important aspect of group composition [23]. It may be problematic, particularly for children, to have large age differences within groups, as the presence of an older child may restrain a younger child's participation. So, it is better to have all participants homogeneous in terms of age [23].

Furthermore, in organising focus groups, participants should feel comfortable with each other in order to create an atmosphere conducive to discussion [13]. Meeting people who have the same characteristics or similar thoughts about a topic would be more attractive than meeting people who differ in this respect. In addition to age, gender has been marked as an important factor in this methodology.

Older children may be so interested in the opposite sex that being part of a mixed group might be very distracting for them [24].

Therefore, in order to get a cross-section of views from a varied population using focus groups, it is essential to have multiple meetings to discuss the same topic. Another point that should be considered is the location of the meetings. The recruitment of participants can be prolonged, particularly if the topic of discussion is not of interest to them.

\section{The Role of the Moderator}

Choosing the moderator is important. If none of the research team members are comfortable to work with the groups or lack the ability to encourage group interaction, researchers can use an external person that has experience in facilitating groups. A good facilitator has the ability to guide discussion and allow the participants to express their views on the topic. A poor moderator controls the discussion and does not promote participation or allows the conversation to 
lose focus [8]. Thus, the moderator's role is critical in clearly explaining the aims of the group, helping people to feel comfortable, and assisting interaction between the participants. Furthermore, moderators need to promote discussion by asking open questions, or challenge participants in order to identify their different views on the topic under discussion. Sometimes the moderator needs to search for details and keep the session focused, or s/he may need to shift the focus of the conversation (e.g. if a minor conclusion is about to be reached). Another role of the moderator is to ensure that all participants have an opportunity to speak. However, moderators should not show excessive approval, nor should they give their personal views in order not to influence participants towards a particular point or opinion [2].

This role is a difficult and challenging one. The moderator needs to possess good personal and communication skills, be a good listener and be flexible. Both natural features of conversation and focused discussion are needed in such a method. This balancing could be achieved by using a welldesigned interview guide which helps group members to calm down, reflect their views, and consider alternatives [9]. Confidence, also, should be promoted between participants to increase the probability of open, interactive discussion. Also, controlling and managing the group depends on the goals of the research and their favoured style. If there is more than one moderator involved in a focus group, they need to agree on how much input or control each will have. Alternatively, one person moderates and the other observes or checks the recording equipment during the session.

The selection of the moderator can have a major impact on focus group results. If focus groups are to be used with children, it is necessary to choose moderators who have worked with children and assign moderators of the same sex as the group participants [23]. A skilled moderator has knowledge when it comes to choosing participants, encouraging them to attend, and interpreting and analysing the data effectively. As a final point, consistency across focus groups needs to be achieved, so careful planning with regard to the role and responsibilities of the moderator is needed.

\section{Important Rules for Conducting Focus Groups}

It is advisable that researchers state some simple rules at the start of the focus group as this can help in the successful facilitation of the group. As suggested by some researchers, such rules may include the following [13]:

(1) One Person Talking at a Time: The group should be informed that it is important that only one person speaks at a time and in case participants need to say something, they can signal the moderator.

(2) Cell Phones Off: the moderator should ask participants to focus on the topic. Therefore, they should be asked to turn off their connections to the outside world.

(3) Confidentiality: the participants should be assured that everything they say will be kept in the room and that no one will be able to relate the obtained data to them. If anyone other than the research team will have an access to the focus group tapes, the researcher is ethically obliged to inform the participants.

Finally, it is better to inform participants in the beginning that if the moderator interrupts them, it is only to ensure that everyone can participate and that the group stays on task.

\section{Ethical Issues}

Ethical issues are an integral part of any qualitative research design. Mainly, approval from ethics committees or their equivalent should be obtained. Focus groups share the same ethical considerations as most other methods of social research [25]. For example, full and clear information about the purpose and uses of the participants' contributions should be given to the participants. Also, the moderator must be honest, and inform participants about the expectations of the group and the topic of the discussion. Furthermore, focus groups may have the potential to produce unpredicted outcomes [16]. Thus, the researcher needs to ensure that the participants are aware of the sensitivity and confidentiality of the data. However, there has been a peculiar ethical issue with regard to focus groups that needs to be considered. This is the handling of sensitive material, and the clarification to participants that their contributions will be shared with the moderator and with other members in the group. Moderators have the responsibility to preserve the anonymity of the data, and they should encourage participants to keep confidential anything that they hear during the focus group meetings.

\section{Conclusion}

The focus group method is considered to be a remarkable tool for collecting information. Using focus groups properly can lead to high quality data for high quality decisionmaking. Researchers seem to agree with the fact that this methodology is more appropriate for generating hypotheses than for testing them. This paper has outlined some issues associated with focus group research, such as the reasons for using the focus group method, its values and limitations, group composition, the role of the moderator, and ethical considerations. It has been revealed that this method can be used to obtain different perspectives on a specific field of interest. Moreover, it could be an empowering process for the participants. However, researchers should consider a number of points when deciding to collect data using this method. That is, they need to pay particular attention to the role of the moderator who should be skilled and sufficiently trained to moderate a group. Also, in the composition of the group, homogeneity needs to be achieved by setting the number, age, and gender of the participants in each group, the times and venues of the meetings, and the types of topic to be considered. The important thing that researchers must keep in mind is the ethical concerns of using focus groups, so consent forms should be used, and the aims of the research 
should be clearly discussed with the participants beforehand.

\section{Acknowledgements}

This Research Project was Supported by a Grant from the Research Centre for the Humanities, Deanship of Scientific Research, King Saud University.

\section{References}

[1] Nyumba, T. O., Wilson, K. A., Derrick, C., \& Mukherjee, N. (2018). The use of focus group discussion methodology: Insights from two decades of application in conservation. Methods in Ecology and Evolution; 9, pp. 20-32.

[2] Krueger, R. A. and Casey, M. A. (2000) Focus Groups: A Practical Guide for Applied Research, 3rd edition. Thousand Oaks, CA: Sage.

[3] House, R. and Howe, K. (1999) Values in Evaluation and Social Research. Thousand Oaks, Calif: Sage.

[4] Kitzinger, J. (1995) 'Introducing focus groups', British Medical Journal, 311, pp. 299-302.

[5] Powell, R. A., Single, H. M. and Lloyd, K. R. (1996) 'Focus groups in mental health research: enhancing the validity of user and provider questionnaires', International Journal of Social Psychology, 42, (3), pp. 193-206.

[6] Morgan, D. L. (1997) Focus groups as qualitative research. London: Sage.

[7] Merton R. K. and Kendall, P. L. (1946) 'The Focused Interview', American Journal of Sociology 51, pp. 541-557.

[8] Nagle, B., \& Williams, A. (2013). Methodology brief: Introduction to focus groups. Center for Assessment, Planning, and Accountability, 1-12.

[9] Morgan, D. L. and Kreuger, R. A. (1993) 'When to use focus groups and why', in Morgan, D. L. (ed), Successful Focus Groups. London: Sage.

[10] Larson, K., N., Grudens-Schuck and Allen, B. L. (2004) Can You Call It a Focus Group? Available at: http://www.extension.iastate.edu/publications/pm1969a.pdf

[11] Folch-Lyon, E. and Trost, J. F. (1981) 'Conducting focus group sessions', Studies in Family Planning, 12, (12), pp. 4439.
[12] McDonald, W. J. and Topper, G. E. (1989) 'Focus-group research with children: A structural approach', Applied Marketing Research, 28, (2), pp. 3-11.

[13] Morgan, D. L. (1988) Focus groups as qualitative research. London: Sage.

[14] Kreuger, R. A. (1988) Focus groups: a practical guide for applied research. London: Sage.

[15] Race, K. E., Hotch, D. F. and Parker, T. (1994) 'Rehabilitation program evaluation: use of focus groups to empower clients', Evaluation Review, 18, (6), pp. 730-40.

[16] Parker, A. and Tritter, J. (2006) 'Focus group method and methodology: current practice and recent debate', International Journal of Research \& Method in Education, 29, (1), pp. 23-37.

[17] Fern, E. F. (2001) Advanced Focus Group Research. Thousand Oaks, Calif: Sage.

[18] Basch, C. (1987) 'Focus group interview: an underutilized research technique for improving theory and practice in health education'. Health Education Q. 14, 411-48.

[19] MacIntosh, J. (1981) 'Focus groups in distance nursing education', Journal of Advanced Nursing, 18, pp. 1981-85.

[20] Powell, R. A. and Single, H. M. (1996) 'Focus groups'. International Journal of Quality in Health Care, 8, 5, 499504.

[21] Tonkiss, F. (2004) 'Using focus groups', in Seale, C. (ed), Researching society and culture. London: Sage Publications, pp. 193-206.

[22] Thomas, L., MacMillan, J., McColl, E., Hale, C., \& Bond, S. (1995). Comparison of focus group and individual interview methodology in examining patient satisfaction with nursing care. Social Sciences in Health, 1, 206-219.

[23] Hoppe, M. J., Wells, E. A., Morrison, D. M., Gilmore, M. R. and Wilsdon, A. (1995) 'Using focus groups to discuss sensitive topics with children', Evaluation Review, 19, (1), pp. 102-14.

[24] Stewart, D. W., \& Shamdasani, P. N. (1990). Focus groups: Theory and practice. Applied social research methods series, Thousand Oaks, CA: Sage Publications, Inc.

[25] Homan, R. (1991) Ethics in Social Research. Harlow: Longman. 